\title{
LA TRAYECTORIA ESCÉNICA DE BIEN VENGAS MAL Y EL MANUSCRITO 15633 DE LA BNE ${ }^{1}$
}

\author{
Alejandro García Reidy \\ Plaza de Andújar 3, pta. 28 \\ 46006 Valencia \\ ESPAÑA \\ alejandro.garcia.reidy@gmail.com
}

[Anuario calderoniano (ISSN: 1888-8046), 4, 2011, pp. 181-199]

UNA COMEDIA DE LA ÉPOCA DE PLENITUD

Bien vengas mal, también conocida por el título Bien vengas mal, si vienes solo ${ }^{2}$, es una comedia urbana de Calderón de la Barca que pertenece a la considerada como década prodigiosa de su producción dra-

${ }^{1}$ Mi trabajo se ha beneficiado de mi vinculación a los proyectos de investigación financiados por el MICINN con los números siguienres de referencia FFI2008-00813 y CDS2009-00033, así como al proyecto Manos Teatrales: An Experiment in CyberPaleography, dirigido por Margaret R. Greer (Duke University).

${ }^{2}$ El título de Bien vengas mal es el que figura en todos los testimonios del siglo XVII conservados de esta comedia, mientras que el de Bien vengal mal, si vienes solo es el título que dio Calderón en la lista de sus obras que remitió al Duque de Veragua, y que aparece también en algunos documentos de la época. 
mática, la de 1630, aunque prácticamente ha pasado desapercibida para la crítica moderna en comparación con otras obras de este periodo. Quizá sin llegar a la perfección de otras comedias urbanas de Calderón, la obra desarrolla una eficaz trama que cuenta con los imprescindibles enredos amorosos, galanteos y celos. Hartzenbusch, su primer editor moderno, la fechó en torno a 1635, aunque con argumentos nada definitivos ${ }^{3}$. Hilborn, basándose en el análisis métrico, también consideró que la obra se escribió hacia $1635^{4}$. Más concluyente resulta el hecho de que la primera noticia que poseemos respecto de la puesta en escena de esta obra sea de finales de este año, como enseguida se verá, lo que sitúa 1635 como terminus ante quem y fecha verosímil para la composición de esta obra.

La desatención moderna hacia esta comedia no implica que careciera de éxito en la escena barroca. La documentación de la época nos ofrece varias noticias acerca de la trayectoria teatral de Bien vengas mal en los años siguientes a su composición. Es probable que Calderón escribiera esta obra para la compañía Tomás Fernández Cabredo, pues el 16 de diciembre de 1635 su formación hizo una representación particular de Bien vengas mal ante el rey en palacio ${ }^{5}$. Podemos suponer que Fernández Cabredo la habría estrenado con su compañía en uno de los corrales madrileños no mucho antes de llevarla a palacio. La siguiente noticia que nos aporta la documentación data del 7 de diciembre de 1640, cuando el autor Francisco Álvarez de Vitoria entregó un memorial al arrendador del Coliseo de Sevilla en el que incluía un listado de las comedias que podía representar. Bien vengas mal, si vienes solo, atribuida explícitamente a Calderón, figura entre las que el autor consideraba «viejas, que puede ser sea alguna nueva entrellas sin ser milagro" (es decir, que alguna comedia de su repertorio podría no haberse representado nunca en Sevilla y ser

${ }^{3}$ Hartzenbusch, 1850, p. 670.

${ }^{4}$ Hilborn, 1938, pp. 20, 34 y 73.

${ }^{5}$ Shergold y Varey, 1961, p. 276. El primero en dar noticia de esta representación fue Cruzada Villaamil, aunque por error omitió el nombre de Tomás Fernández (Cruzada Villaamil, 1871, pp. 106-107). Esto llevó posteriormente a Rennert y Cotarelo a pensar que en realidad la representación de 1635 corrió a cargo del autor Juan Martínez (Rennert, 1906-1907, p. 334, y Cotarelo, 1922, p. 168), que es quien figura mencionado en la entrada inmediatamente anterior a la noticia de esta representación de Bien vengas mal en el artículo de Cruzada Villaamil. 
considerada por ello "nueva», pese a ser una comedia ya representada en otros lugares) ${ }^{6}$.

No sabemos exactamente cómo consiguió Álvarez de Vitoria su copia de la obra, aunque probablemente Fernández Cabredo se la vendió. Sobre esto volveré más adelante. Quizá incluso la muerte de Fernández Cabredo en 1640 llevó a su viuda a deshacerse de algunas comedias viejas vendiéndolas a otras formaciones. En todo caso, Álvarez de Vitoria siguió en posesión de su copia de Bien vengas mal al menos un año más, pues en octubre de 1641 la compañía que dirigía con Pedro Cobaleda y Francisco Vélez de Guevara representó la obra en Sevilla7. Ésta es la última noticia que la documentación nos aporta sobre Bien vengas mal hasta su tardía publicación en 1691, cuando Juan de Vera Tassis la incluyó en la Novena parte de comedias del célebre poeta don Pedro Calderón de la Barca, no sin que el editor pasara por algunas dificultades para hacerse con el texto ${ }^{8}$. A esta primera edición siguió un número significativo de sueltas salidas de diferentes prensas peninsulares desde finales del siglo XVII y durante todo el siglo XVIII ${ }^{9}$.

${ }^{6}$ Bolaños Donoso, 1997-1998, pp. 57-59.

7 Sentaurens, 1984, p. 1096.

${ }^{8} \mathrm{Al}$ publicar en 1684 su Obelisco fúnebre, Gaspar Agustín de Lara incluyó una lista de comedias de Calderón, entre las que figuraba Bien vengas mal. Sin embargo, cuando al año siguiente Vera Tassis publicó su edición de la Primera parte de comedias de Calderón, negó en el prólogo dirigido «Al que leyere» que esta comedia fuera de Calderón: «ni este [i.e., Los obreros del Señor] ni Bien vengas mal, si vienes solo, se había de arrojar don Pedro, dejando de poner más de veinte grandes comedias» (Calderón

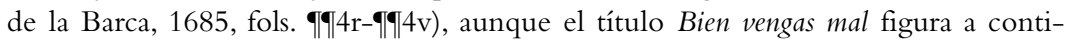
nuación en el listado de comedias que Vera Tassis pensaba publicar en la Novena parte. Cuando en 1691 apareció finalmente esta parte, Vera Tassis se disculpó por haber rechazado la atribución de esta comedia a Calderón con la excusa de que había visto «otra con el mismo título, y registrando ésta que ahora te presento, reconozco por lo artificioso de la traza y la naturaleza del verso que es legítimo parto suyo» (Calderón de la Barca, 1691, fol. \8r). Sobre el problema de la configuración del corpus calderoniano en el siglo XVII y el conocimiento real por parte de Vera Tassis de las obras auténticas y espurias de Calderón, ver Coenen, 2009.

${ }^{9}$ Reichenberger, 1979 , pp. 155-157. La comedia tuvo también cierto éxito sobre los escenarios durante el siglo XVIII y fue refundida a principios del XIX. Al respecto, ver González Cañal, 2010. 


\section{LA COPIA MANUSCRITA DE BIEN VENGAS MAL}

En el presente trabajo me centraré en un testimonio concreto de Bien vengas mal, el cual aporta nuevos datos sobre la trayectoria escénica de esta comedia y su circulación entre diversas compañías del siglo Xvir. Se trata de una copia manuscrita parcial del texto, que actualmente se conserva en la Biblioteca Nacional de España bajo la signatura Ms. $15633^{10}$. El manuscrito tiene un tamaño corriente de 215 x $150 \mathrm{~mm}$., consta de cuarenta y cuatro folios (cuarenta y tres con el texto de la comedia), más una hoja de guarda, y contiene sólo las dos primeras jornadas de la obra; la tercera jornada ya se había perdido cuando se catalogó como parte de la biblioteca del Duque de Osuna a finales del siglo XIX ${ }^{11}$. Como trataré en detalle más adelante, el manuscrito fue copiado por tres manos distintas, todas del siglo XVII.

En la hoja de guarda delantera encontramos la primera indicación de la vinculación de este manuscrito a una compañía: alguien escribió el título de la comedia y la autoría de Calderón, añadiendo a continuación "de Antonio de Escamilla», lo que apunta a la pertenencia de este manuscrito a este afamado actor y autor de comedias. No es ésta la única marca en el manuscrito que denota su condición de artefacto teatral inserto en la práctica escénica barroca: en el recto del folio que antecede al comienzo de la comedia se incluye un reparto completo de los actores a los que se les asignaron los papeles de la obra para una representación, de la misma mano que copia los primeros folios del manuscrito. La transcripción es como sigue:

$\begin{array}{ll}\text { Don Luis } & \text { Felipe Domínguez } \\ \text { Guzmán, criado } & \text { Salvador } \\ \text { Don Juan de Lara } & \text { Jacimo [sic] } \\ \text { Don Diego de Silva } & \text { Castro } \\ \text { Espinel } & \text { Cosme }\end{array}$

${ }^{10}$ Paz y Melia, 1934, p. 60.

11 Rocamora, 1882, p. 59, n. 330. El manuscrito está formado por dos cuadernillos diferentes: el primero comprende los fols. $1 \mathrm{r}-31 \mathrm{v}$ (cuadernillo de treinta y dos folios) y el segundo los fols. 32r-43v (cuadernillo de doce folios), cada uno de los cuales emplea papel diferente, como demuestran sus filigranas (dos diferentes por cada cuadernillo). Es posible que la tercera jornada se copiara en otro cuadernillo de doce folios y que éste se desgajara de la encuadernación con el tiempo y se perdiera. 
Don Bernardo, viejo

$\mathrm{D}^{\mathrm{a}}$ Ana

$\mathrm{D}^{\mathrm{a}}$ María

Inés, criada

Juana
Autor

$\mathrm{S}^{\mathrm{a}}$ Inés de Hita

$\mathrm{S}^{\mathrm{a}}$ Isabel de Góngora

$\mathrm{S}^{\mathrm{a}}$ Jusepha [sic]

$S^{a}$ Mariana

El primero en dar cuenta de este reparto e intentar identificar a sus integrantes fue Cotarelo y Mori, quien en 1922 recogió los datos bibliográficos esenciales del manuscrito y transcribió el reparto, completando entre paréntesis los nombres de la mayoría de los actores y actrices en él presentes. De acuerdo con su propuesta, el actor llamado «Salvador» en el reparto sería el actor Jaime Salvador, «Jacinto» (según la lectura de Cotarelo) sería Jacinto Varela, «Cosme» sería Cosme Pérez, la «Señora Jusepa» sería Josefa Lobaco y la «Señora Mariana» sería Mariana de Olivares; el «autor» sería Roque de Figueroa. El actor que figura en el reparto como "Castro" quedó sin identificar por parte del erudito asturiano. La nómina del reparto ofrecido por Cotarelo se completa con los actores Felipe Domínguez, Inés de Hita e Isabel de Góngora. Ahora bien, Cotarelo no aportó ningún dato que avalara las identificaciones de cada uno de estos actores, especialmente en lo referente a la identificación del «autor» con Roque de Figueroa. Tampoco propuso ninguna fecha concreta para el reparto; tan sólo notó que la «copia es posterior, como se ve por el nombre de Escamilla, pero el reparto es el primitivo» ${ }^{12}$.

En 1961 Shergold y Varey dieron también noticia de este manuscrito. Aunque los dos hispanistas recogieron la opinión de Cotarelo de que el reparto era "primitivo", no mencionaron su atribución a la compañía de Figueroa y señalaron, en cambio, las dificultades que existían para identificar el reparto con la compañía que estrenó la obra o con la que la representó en palacio a finales de 1635 ("the preliminary page bearing the name of Escamilla is probably of a later date than the cast list, but it cannot be proved from the names of the actors that this is the original cast list, nor that which performed the play in 1635»), llegando incluso a dudar de que la copia se hiciera para la compañía de Escamilla ${ }^{13}$.

12 Cotarelo y Mori, 1922, p. 168, n. 1.

13 Shergold y Varey, 1961, pp. 276-277. 
Por último, José María Ruano de la Haza prestó brevemente atención a este reparto en su estudio sobre Sebastián de Alarcón y Antonio de Escamilla como copistas de obras calderonianas ${ }^{14}$. En este trabajo Ruano ofreció su propia transcripción del reparto, con la novedad de ofrecer la correcta lectura de "Jacimo» como el nombre del actor al que se asignó el papel de «Don Juan de Lara» y el incorrecto de "S $\mathrm{S}^{\mathrm{a}}$ Juscosa [?]» para la actriz que interpretó a «Inés, criada». Ruano tan sólo sugirió que "Jacimo» pudo ser el actor Jacinto Becerril. Respecto a la compañía a la que corresponde el reparto, Ruano expresó sus dudas — bien justificadas, como veremos — de que pudiera ser la de Antonio de Escamilla ${ }^{15}$.

Las observaciones hechas por Cotarelo, Shergold y Varey, y Ruano de la Haza constituyen un punto de partida ineludible a la hora de estudiar el manuscrito de Bien vengas mal, pero al mismo tiempo dejan abiertos muchos interrogantes que iré aclarando a lo largo de las páginas siguientes.

\section{LOS ACTORES Y ACTRICES DEL REPARTO}

Comencemos por identificar a los miembros del reparto. El mejor punto de inicio lo constituyen los actores cuya identidad no presenta problemas: Felipe Domínguez, Inés de Hita e Isabel de Góngora. La actividad dramática profesional de Isabel de Góngora, apodada la Góngora, está documentada entre 1632, cuando fue recibida en la Cofradía de Nuestra Señora de la Novena como miembro de la compañía de Cristóbal de Avendaño, y 1653, último año en el que sabemos que estuvo activa como profesional. Isabel formó parte de la compañía de Antonio García de Prado que representó en Madrid de 1635. El 15 de marzo de 1636, sin embargo, cambió de compañía al firmar un contrato con Pedro de la Rosa para representar con él durante un año. Rosa, que había iniciado su carrera como actor en la compañía de Tomás Fernández Cabredo, la había abandonado en la primavera del año 1636 para encabezar su propia formación. La vinculación de Isabel de Góngora con Pedro de la Rosa fue larga y fructífera: la actriz trabajó en esta compañía durante dieciséis años, probablemente de

14 Ruano de la Haza, 1978, p. 78.

15 Ruano de la Haza, 1978, p. 78. 
manera ininterrumpida, pues hay noticias de su pertenencia a esta formación en 1637-1642, 1644, 1649, 1650 y $1652^{16}$. Es probable que Isabel de Góngora se especializara representando los papeles de segunda dama en la compañía de Rosa, porque así se indica no sólo en la primera escritura que firmó con este autor, en 1636, sino también en la documentación relativa al año 1639. Precisamente en el reparto de Bien vengas mal se le asigna el papel de segunda dama de la obra, el de doña María. A la altura de la primavera de 1653 había abandonado finalmente la compañía de Rosa y entrado a formar parte de la de Juan Vivas. Ante estos datos, la hipótesis de Cotarelo de que el reparto corresponde a la compañía de Roque de Figueroa no se sostiene: la trayectoria profesional de Isabel de Góngora no la vincula en ningún momento a esta formación. En cambio, el nombre de Pedro de la Rosa aparece como una alternativa interesante por la larga vinculación de Isabel de Góngora con este autor, posibilidad que habrá que confrontar con el resto del reparto.

La otra actriz claramente identificada en el reparto, Inés de Hita, estuvo en la compañía encabezada por su marido, Francisco Pinelo, en los años 1632, 1635, 1636 y 1637, con una estancia en la compañía de Juan de Morales Medrano en 1633. Después existe una laguna en la documentación entre 1638 y 1640, cuando se la documenta de nuevo ejerciendo como actriz en la compañía de Andrés de la Vega ${ }^{17}$. Respecto al actor que interpretó el papel del galán protagonista, Felipe Domínguez, entre 1633 y 1636 estuvo representando con tres compañías diferentes: José de Salazar Mahoma, Fernán Sánchez de Vargas y Juan de Peñalosa. No tenemos noticias acerca de su actividad profesional entre 1637 y 1639 , hasta que se le vuelve a documentar en febrero de 1640, cuando aparece como miembro en la compañía de Andrés de la Vega. Al año siguiente pasó a convertirse en co-autor de esta formación. Desempeñó los papeles de primer galán en esta compañía conjunta y meses más tarde pasó a dirigir su propia formación, con la que estuvo activo al menos durante 1643 y $1644^{18}$.

Si cotejamos las noticias disponibles sobre la actividad dramática de Isabel de Hita y de Felipe Domínguez con la de Isabel de Góngora,

$\begin{array}{ll}16 & \text { Ferrer Valls, } 2008 . \\ 17 & \text { Ferrer Valls, } 2008 . \\ 18 & \text { Ferrer Valls, } 2008 .\end{array}$

Anuario calderoniano, 4, 2011, pp. 181-199. 
nos encontramos ante el hecho de que no existe punto de encuentro alguno entre estos tres actores. Es decir, que no se documenta positivamente en ningún momento la pertenencia de los tres actores a la misma compañía. Al contrario, en prácticamente todos los años donde está documentada su actividad teatral cada uno se encontraba trabajando en una compañía distinta, usualmente en lugares diferentes de la geografia peninsular, y si en 1640 Isabel de Hita y Felipe Domínguez coincidieron en la compañía de Andrés de la Vega, la Góngora seguía representando con Pedro de la Rosa. ¿Qué ocurre con el reparto en el manuscrito de Bien vengas mal, donde coinciden los tres? En este caso, debemos fijarnos en los silencios de la documentación teatral sobre la actividad profesional de Hita y Domínguez. Ante los datos disponibles constatamos que carecemos de noticias sobre su actividad para los años 1638 y 1639. En este punto, los datos me llevan a plantear la siguiente hipótesis: por eliminación, el reparto de Bien vengas mal pertenece a algún momento de este bienio, pues es imposible que pudiera ser de ningún otro año por la incompatibilidad en las trayectorias profesionales de los tres actores claramente identificados en él. Y pues está documentado fehacientemente que Isabel de Góngora perteneció a la compañía de Pedro de la Rosa tanto en 1638 como en 1639, la hipótesis lógica consiste en suponer que el reparto correspondería a su formación.

Para poder corroborar esta hipótesis o, al menos, dotarla de la mayor consistencia posible, el resto de miembros del reparto también deberán estar vinculados a la compañía de Pedro de la Rosa en 1638 o 1639, o al menos no podrán estar documentados formando parte de otras compañías durante estos dos años. Fijémonos en primer lugar en el actor Cosme, que representó el papel del gracioso Espinel en la comedia calderoniana. Cotarelo supuso que se trataba del célebre actor Cosme Pérez, apodado Juan Rana, identificación que considero correcta. DICAT sólo documenta la actividad de cinco actores con el nombre de Cosme y cuatro de ellos estuvieron activos en fechas demasiado tempranas o tardías. Sólo Cosme Pérez estuvo activo al mismo tiempo que Isabel de Góngora. Y lo que más nos interesa: Juan Rana está documentado como miembro de la compañía de Pedro de la Rosa en los años 1638-163919. La vinculación de este actor con la

${ }^{19}$ Ferrer Valls, 2008. 
compañía de Rosa fue larga, al igual que en el caso de la Góngora. Rosa y Cosme ya coincidieron en la compañía de Tomás Fernández Cabredo en 1635 y principios de 1636. Poco después de que Rosa se desvinculara de esta compañía para formar la suya propia, Cosme Pérez pasaría a trabajar para él, habiendo logrado ya para esas fechas un nombre para su personaje de Juan Rana, como señala Sáez Raposo ${ }^{20}$. El 16 de febrero de 1637 Cosme Pérez firmó un concierto con Rosa para representar en su compañía «la parte principal de graciosidad» ${ }^{21}$, y con él trabajaría en calidad de gracioso durante los años 1638-1639, 16411644 y 1646, y es verosímil suponer que también lo hiciera en 1640 (en 1645 los teatros castellanos estuvieron clausurados). En 1648 pasó a integrarse en la compañía de Antonio García de Prado, poniendo fin así a su relación profesional con Pedro de la Rosa.

Respecto al actor que representó el otro papel de gracioso en Bien vengas mal, el del criado Guzmán, en el reparto figura tan sólo con el nombre o apellido de Salvador. Cotarelo lo identificó con el actor Jaime Salvador y, de nuevo, coincido con la propuesta del erudito investigador, pues está documentado que Jaime Salvador perteneció a la compañía de Pedro de la Rosa en torno a los años que nos interesan. Así, el 3 de febrero de 1637 se concertó con Rosa para representar en su compañía durante un año y, aunque no tenemos noticia de su actividad en 1638, aparece como miembro de la compañía de Rosa que representó en las fiestas del Corpus de Sevilla de 1639. En la documentación sevillana figura como segundo gracioso de la formación de Rosa, mientras que los papeles de primeros graciosos corrieron a cargo de Juan Rana ${ }^{22}$, lo que encaja con los papeles que se asignaron a ambos actores en el reparto de Bien vengas mal. Es más, Jaime Salvador y Cosme Pérez formaron pareja cómica durante los años que coincidieron tanto en la compañía de Tomás Fernández Cabredo como en la de Pedro de la Rosa, tal y como demuestran los repartos de varias piezas de Quiñones de Benavente fechadas por Bergman entre 1634 y $1640^{23}$. Su presencia en el reparto de Bien vengas mal apuntaría a esta buena sintonía en el escenario.

\footnotetext{
20 Sáez Raposo, 2005, pp. 29-30.

21 Pérez Pastor, 1901, pp. 244-245.

22 Ferrer Valls, 2008.

23 Bergman, 1965, p. 544.
} 
En cuanto al actor que aparece en el reparto como «Jacimo», creo con Cotarelo que se trata de una errata o descuido del copista por «Jacinto». DICAT recoge noticias de treinta actores con este nombre (o apellido), varios de los cuales estuvieron activos profesionalmente durante las fechas que nos interesan. Cotarelo pensó que se trataba de Jacinto Varela, identificación que se ajustaría a su hipótesis de que el reparto pertenece a la compañía de Roque de Figueroa, por cuanto Varela fue miembro de esta formación en 1626. No obstante, es imposible que Jacinto Varela fuera el actor que encarnara el papel de Don Juan de Lara, pues murió en 1634 y, como propongo, el reparto de Bien vengas mal es posterior a $1635^{24}$. Ruano de la Haza, por su parte, pensó que este actor pudo ser Jacinto Becerril. Frente al caso de Jacinto Varela, es una identificación verosímil, pero ninguna de las noticias disponibles lo vincula con Pedro de la Rosa y, en cambio, está documentado que en marzo de 1639 firmó un contrato para representar en una formación diferente. Por ello, me parece que esta identificación no cuenta con fundamentos demasiado sólidos, sobre todo cuando hay un actor que se ajusta a mi hipótesis. Se trata de Jacinto de Barrios, de quien apenas tenemos dos noticias, aunque ambas lo vinculan precisamente a la compañía de Pedro de la Rosa: figura en la lista de actores de la compañía de Rosa que participaron en las fiestas del Corpus de Sevilla de 1639, donde se indica que representaba los papeles de tercer galán, y en 1640 falleció en Lisboa mientras representaba con la compañía de $\operatorname{Ros}^{25}$. Creo que éste es el actor al que se asignó el papel de Don Juan de Lara en el reparto, un papel que casi se acerca más al de segundo galán.

La identificación del actor que aparece en el reparto como Castro es más complicada que el resto. Después de revisar los datos del más de medio centenar de actores con este apellido contenidos en DICAT, dos son los actores con los que se podría identificar a este Castro, aunque con muchas dudas. El primero sería Jerónimo de Castro, de quien existe una laguna en la documentación que comprende los años 16361639. En 1640 se representó con Antonio García de Prado, cuya formación que había coincidido con la de Pedro de la Rosa el año anterior en Sevilla, de manera que no es descartable pensar que Jerónimo

${ }^{24}$ Ferrer Valls, 2008.

${ }^{25}$ Ferrer Valls, 2008. 
de Castro pasó de una compañía a otra por esas fechas. La segunda opción posible es Juan de Castro y Salazar, activo ya en 1636, aunque sólo tenemos documentada su carrera de manera más constante desde $1642^{26}$. Por el momento, queden como las posibilidades menos conflictivas con los datos disponibles.

En cuanto al «Autor» al que se asignó el papel de «Don Bernardo, viejo", si mi hipótesis es correcta se trataría de Pedro de la Rosa. Es interesante señalar que hacia 1638-1639 Rosa no era en absoluto un hombre mayor, pues nació en 1613 o 1614; contaba, por lo tanto, con unos veinticinco años cuando representó este papel de "viejo», aunque está documentado que otros actores relativamente jóvenes encarnaron papeles de barbas $^{27}$. O bien en el momento en el que se iba a representar Bien vengas mal la compañía de Pedro de la Rosa no disponía de un actor especializado en los personajes de barbas, o bien por circunstancias desconocidas éste no pudo representar en dicho momento y hubo de ser sustituido por Rosa. El attrezzo de su compañía, que sin duda debía de contar con barbas postizas, permitió la metamorfosis adecuada para que un actor joven pudiera representar verosímilmente el papel de padre.

Vistos los papeles asignados a actores, pasaré a considerar los de las actrices. Ya hemos comprobado que dos de ellas, Inés de Hita e Isabel de Góngora, no presentan problemas en su identificación. De las dos que quedan, la que figura en el reparto como " $S^{a}$ Jusepha» (es decir, «señora Josefa) es la que ofrece menos dificultades. Los datos disponibles apuntan a que se trata de Josefa Román, y no Josefa Lobaco, como creyó Cotarelo. Ambas representaron en las fiestas del Corpus de Sevilla de 1639, pero Josefa Lobaco lo hizo en la compañía de Antonio García de Prado, mientras que Josefa Román representó con la formación de Rosa, donde se encargaba de los papeles de terceras damas, lo que se ajusta al tipo de personaje que tuvo que interpretar en Bien vengas mal. Fue, de hecho, celebrada por su pericia con este tipo de papeles, como

${ }^{26}$ Ferrer Valls, 2008.

27 Es el caso de José de Carrión, quien ya en 1639 estaba especializado en este tipo de papel. Aunque no sabemos con seguridad la fecha de su nacimiento, no debía de ser muy mayor en ese año, pues su carrera se desarrollaría durante casi cuatro décadas más después de 1639 (Ferrer Valls, 2008). 
se refiere en la Loa con que empezó Tomás Fernández en la Corte ${ }^{28}$. Sabemos que, al igual que Isabel de Góngora, Josefa Román abandonó la formación de Tomás Fernández Cabredo a principios de 1636 para acompañar a Pedro de la Rosa en la compañía que éste comenzó entonces a dirigir. Está documentada su presencia en la formación en 1637 y, aunque no tenemos noticias de su actividad en 1638, es probable que también trabajara con Rosa en este año.

Queda, por último, la actriz que aparece en el reparto simplemente con el nombre de Mariana, a la que se asigna el papel de la criada Juana. Esta identificación es mucho más complicada que el resto de los casos, pues no hay constancia de ninguna actriz con este nombre que trabajara con Pedro de la Rosa en las fechas que nos interesan. Respecto a la identificación con Mariana de Olivares propuesta por Cotarelo en su día, el que esta actriz fuera la esposa de Roque de Figueroa y, por lo tanto, representara exclusivamente con la compañía de su marido me lleva a rechazar tal identificación. Por desgracia, un estudio exhaustivo de la información contenida en DICAT no permite llegar a ninguna identificación verosímil. Varias son las actrices a las que puede corresponder esta Mariana: por ejemplo, Ana María de Peralta y Escobedo, que aparece en algunos documentos como Mariana de Peralta, de la cual no hay noticias en los años 1638 y 1639. Algo similar sucede con Mariana de Aparicio, documentada como actriz en 1633, 1634 y 1636. O quizá pudo ser Mariana de Ribera, quien también trabajó en torno a la década de 1630, sin que la tengamos documentada en 1638 o $1639^{29}$. En este caso, las lagunas documentales constituyen en un impedimento demasiado grande como para poder ofrecer una hipótesis razonable de identificación.

Tras este análisis individualizado de cada uno de los nombres, mi propuesta de identificaciones completaría el reparto de la siguiente manera:

Don Luis

Felipe Domínguez

Guzmán, criado [Jaime] Salvador

28 «Qué sentiré oyendo esto, / yo, que las terceras hago, / cuando Antonia [Infante] es un portento / y Josefa [Román] es un milagro?» (Bergman, 1965, pp. 297 y 534).

${ }^{29}$ Ferrer Valls, 2008. 
Don Juan de Lara

Don Diego de Silva

Espinel

Don Bernardo, viejo

$\mathrm{D}^{\mathrm{a}}$ Ana

$\mathrm{D}^{\mathrm{a}}$ María

Inés, criada

Juana
Jacinto [de Barrios]

[¿Jerónimo o Juan de?] Castro

Cosme [Pérez]

Autor [Pedro de la Rosa]

$S^{a}$ Inés de Hita

$\mathrm{S}^{\mathrm{a}}$ Isabel de Góngora

$\mathrm{S}^{\mathrm{a}}$ Josefa [Román]

$S^{a}$ Mariana

¿Es posible fijar con mayor precisión la fecha a la que corresponde este reparto? De entrada, tiene que ser necesariamente posterior a enero de 1638, cuando Inés de Hita se encontraría representando en la compañía de su marido, Francisco Pinelo, y anterior al 9 de febrero de 1640, cuando está documentado que Felipe Domínguez era miembro de la compañía de Andrés de la Vega. Contamos con algunos documentos que ofrecen datos sobre la composición de la compañía de Pedro de la Rosa en el período 1638-1639, los cuales pueden ayudar a precisar un poco la fecha del reparto. Por un lado, en una escritura que firmó con el clavario del Hospital General de Valencia el 10 de marzo de 1638, Rosa se concertó para ir a esta ciudad a representar a partir de junio, comprometiéndose a que acudirían con él ciertos miembros de la formación: Francisco Velasco, Cosme Pérez, la Góngora, Antonia de Santiago y la mujer de Rosa, Catalina Nicolás ${ }^{30}$. Como se ve, dos de estos actores (Cosme Pérez e Isabel de Góngora) figuran en el reparto de Bien vengas mal, mientras que los otros tres están ausentes de él. Entre las noticias referidas al año 1639, la ya mencionada documentación del Corpus sevillano ofrece un listado de la compañía con la que Pedro de la Rosa trabajó en junio de ese año, que incluye veintiún actores y actrices, lo que parece indicar que se trata del listado completo de su formación ${ }^{31}$. Junto a los actores que he identificado con cinco nombres presentes en el manuscrito (Jacinto de Barrios, Isabel de Góngora, Josefa Román, Cosme Pérez Juan Rana y Jaime Salvador), figuran bastantes otros que no aparecen en él, mientras que otros actores que también aparecen en el reparto (Inés de Hita, Felipe Domínguez, Castro y Mariana) no se incluyen

${ }^{30}$ Ferrer Valls, 2008.

${ }^{31}$ Ferrer Valls, 2008. 
en este listado. A partir de estos datos, me parece que el reparto puede fecharse entre el comienzo de la temporada de 1638 y antes de junio de 1639, cuando algunos de los actores que figuran en el reparto (los mencionados Hita, Domínguez, Castro y Mariana) ya no formaban parte de la compañía de Pedro de la Rosa. Quizá corresponda a la temporada de 1638-1639, que la compañía de Rosa pasó en Valencia y Andalucía.

El manuscrito en la trayeCtoria escénica de BIEN VENGAS MAL

Dado que Bien vengas mal fue estrenada por Tomás Fernández Cabredo, hay que responder a la cuestión de cómo llegó el texto a manos de Pedro de la Rosa. He señalado que Rosa comenzó a dirigir su propia formación en 1636 tras haber trabajado en la de Fernández Cabredo. Es verosímil pensar que el propio Rosa, junto con Cosme Pérez, Jaime Salvador y Josefa Román, pudieron representar Bien vengas mal cuando formaban parte de la compañía de Tomás Fernández en 1635, e incluso pudieron participar en la representación que se hizo de esta obra en palacio en diciembre de ese año. Por lo tanto, Rosa tuvo acceso al texto de esta comedia calderoniana por haber sido miembro de la compañía que la estrenó. Ahora bien, sabemos que durante los primeros años en los que Rosa tuvo compañía propia representó en palacio obras que pertenecieron al repertorio de Tomás Fernández. Bergman documentó los casos de El galán fantasma y Progne y Filomena ${ }^{32}$, a los que podemos añadir El galán sin dama y Celos, honor y cordura ${ }^{33}$, y ahora también Bien vengas mal. La citada investigadora pensó que esta coincidencia apuntaría a un caso de piratería entre compañías, aunque, al ser varias las comedias representadas por ambas compañías en fechas cercanas, parece más verosímil suponer que Rosa compró a Tomás Fernández copias de estas obras cuando abandonó su compañía para formar la suya propia. Además, no existen noticias de enemistad entre Tomás Fernández y Rosa, y ambos autores colaboraron en las fiestas de San Juan de 1636 que se celebraron en el Retiro y coincidieron en el Corpus madrileño de $1637^{34}$.

\footnotetext{
32 Bergman, 1965, p. 287, n. 20a.

33 Sobre estas representaciones, ver Ferrer Valls, 2008.

34 Ferrer Valls, 2008.
} 
Ahora bien, ciertos aspectos del manuscrito de Bien vengas mal apuntan a que la copia en sí es bastante posterior a la fecha del reparto. Ya señalé que una anotación en el manuscrito indica que perteneció al autor Antonio de Escamilla y, lo que es más importante, puede identificarse como suya una de las manos que intervinieron en la copia. Tal y como se recoge en la base de datos de Manos Teatrales ${ }^{35}$, el manuscrito de Bien vengas mal fue copiado por tres personas diferentes: la primera de ellas comenzó el traslado (incluyendo el reparto) y llegó hasta el primer verso del folio 16v; la segunda mano se hizo entonces cargo de la copia y siguió hasta llegar al folio $31 \mathrm{v}$; por último, la tercera mano copió los folios 32r-43r. Los intentos por identificar al tercer copista han sido infructuosos, pero la primera mano es de Miguel de Escamilla y la segunda, como ya señaló en su día Ruano, corresponde a la de su abuelo, Antonio de Escamilla ${ }^{36}$. Esto sitúa la fecha del manuscrito en la segunda mitad del siglo xviI, cuando Antonio desarrolló su carrera teatral, y es posible que pueda ser de hacia 1689-1690, cuando sabemos que Miguel de Escamilla colaboró en el traslado de otros dos manuscritos para la compañía de su abuelo ${ }^{37}$. En este sentido, Cotarelo estuvo en lo cierto cuando afirmó que el reparto era "primitivo" en relación con la fecha del manuscrito.

¿Cómo explicar la presencia de un reparto de la compañía de Pedro de la Rosa en un manuscrito copiado décadas más tarde y en posesión de Antonio de Escamilla? Con los datos existentes, me parece que la explicación más verosímil es la siguiente:Tomás Fernández Cabredo, poseedor del original de Bien vengas mal, vendió una copia a Pedro de la Rosa entre 1636 y 1638. La compañía de Rosa representó la comedia en torno a este último año y la distribución de papeles se plasmó en forma de reparto en la copia que poseía Rosa, la cual adquiriría Antonio de Escamilla años después. Sabemos que Antonio de Escamilla fue miembro de la compañía de Rosa a principios de 1660, y que incluso pasó a dirigir la formación, probablemente por enfermedad de dicho autor, convirtiéndose de facto en su director. Quizá

35 El manuscrito tiene el id. 1015 en esta base de datos, a la que remito para más detalles. Manos Teatrales se encuentra actualmente alojada en la página web $<\mathrm{http}: / / \mathrm{ma}-$ nosteatrales.org> (consultada el 1 de febrero de 2011).

${ }^{36}$ Manos Teatrales, ms. 1015; Ruano de la Haza, 1978, p. 178.

37 Los manuscritos son copias de La dama duende, con fecha de 1689, y de Pedro de Urdemalas, fechado en 1690 (Manos Teatrales, ms. 1058 y ms. 1475). 
Escamilla, al convertirse en cabeza de lo que había sido la compañía de Rosa, pudo entonces adquirir de este actor varios de los manuscritos teatrales que éste poseía para disponer de un repertorio propio. En todo caso, Escamilla consideró necesario hacer un nuevo traslado del texto y, cuando su nieto Miguel comenzó a sacar la copia a partir del manuscrito de Rosa, copió también (tal vez mecánicamente) el reparto que en él figuraba, pese a que correspondía a una representación hecha por otra compañía décadas atrás ${ }^{38}$. La copia fue luego proseguida por Antonio y el tercer copista ${ }^{39}$.

Cuestión aparte es la importancia del manuscrito en la transmisión textual de esta comedia, en particular respecto a la versión publicada por Vera Tassis en 1691. El análisis ecdótico de estos dos textos merece un detallado estudio por sí mismo, pero señalaré que un somero y selectivo cotejo entre el texto del manuscrito y el impreso por Vera Tassis revela que no existe una dependencia directa entre los dos. En la muestra manejada el manuscrito presenta mayores errores de lectura en comparación con el texto impreso, aunque también existen variantes adiáforas y el manuscrito presenta alguna que otra lectura que mejora la versión de Vera Tassis. Los datos que presento en este artículo apuntan a que entre el manuscrito de la Biblioteca Nacional y el original calderoniano posiblemente medió sólo la copia que poseyó Pedro de la Rosa, por lo que no es descartable que alguna de estas lecturas pudiera ser más cercana al original de Calderón que el texto empleado por Vera Tassis.

En conclusión, el manuscrito 15633 de la Biblioteca Nacional de España se revela como una pieza atractiva en el conjunto de la trayectoria escénica de Bien vengas mal: por un lado, el reparto que en él figura documenta que la compañía del autor Pedro de la Rosa poseyó y representó esta comedia en torno a 1638-1639; por otro lado, la vinculación del manuscrito con Antonio de Escamilla muestra que la comedia todavía circulaba entre las compañías profesionales (y pudo representarse) en la segunda mitad del siglo XVII, décadas después de su composición. Este manuscrito se nos presenta, en definitiva, como

38 Todo esto hace que me parezcan infundadas las dudas de Shergold y Varey, ya mencionadas antes, de que el manuscrito de Bien vengas mal se copiara para la compañía de Escamilla (Shergold y Varey, 1961, pp. 276-277).

${ }^{39}$ Dado que no se tienen noticias de los folios donde se habría copiado la tercera jornada, es imposible saber qué copistas intervinieron en su traslado. 
un complejo artefacto teatral que codifica en anotaciones en él presentes (el reparto) y en los trazos mismos de la escritura (la caligrafía de los copistas) valiosa información que arroja luz sobre la historia de esta comedia calderoniana. 


\section{BIBLIOGRAFÍA}

Bergman, H. E., Luis Quiñones de Benavente y sus entremeses: con un catálogo biográfico de los actores citados en sus obras, Madrid, Castalia, 1965.

Bolaños Donoso, P., «Lorenzo Hurtado y el año dramático sevillano de 1640-1641», Diablotexto, 4-5, 1997-1998, pp. 43-59.

Calderón de la Barca, P., Bien vengas mal, Biblioteca Nacional de España, ms. 15633.

- Primera parte de comedias del célebre poeta español don Pedro Calderón de la Barca... que nuevamente corregidas publica don Juan de Vera Tassis y Villarroel, Madrid, Francisco Sanz, 1685.

- Novena parte de comedias del célebre poeta español don Pedro Calderón de la Barca... que nuevamente corregidas publica don Juan de Vera Tassis y Villarroel, Madrid, Francisco Sanz, 1691.

Coenen, E., «En los entresijos de una lista de comedias de Calderón», Revista de Filología Española, 89, 1, 2009, pp. 29-56.

Cotarelo y Mori, E., «Ensayo sobre la vida y obras de don Pedro Calderón de la Barca», Boletín de la Real Academia Española, 9, 1922, pp. 17-70, 163208, 311-344, 429-470 y 605-649.

Cruzada Villaamil, G., "Teatro antiguo español. Datos inéditos que dan a conocer la cronología de las comedias representadas en el reinado de Felipe IV, en los sitios reales, en el Alcázar de Madrid, Buen Retiro y otras partes, sacados de los libros de gastos y cuadernos de nóminas de aquella época que se conservan en el archivo del Palacio de Madrid», El Averiguador (Segunda Época), 1, 1871, pp. 7-11, 25-27, 73-75, 106-108, 123-125, 170-172 y 201-202.

Ferrer Valls, T. (dir.), Diccionario biográfico de actores del teatro clásico español (DICAT), Kassel, Reichenberger, 2008.

González Cañal, R., "Fortuna y trayectoria escénica de una comedia calderoniana: Bien vengas, mal, si vienes solo», Anuario calderoniano, 3, 2010, pp. 137-153.

Hartzenbusch, J. E. (ed.), P. Calderón de la Barca, Comedias de don Pedro Calderón de la Barca. Tomo IV, Madrid, Rivadeneyra, 1850.

Hilborn, H. W., A Chronology of the Plays of D. Pedro Calderón de la Barca, Toronto, Toronto University Press, 1938.

Manos Teatrales, base de datos digital dirigida por Margaret R. Greer y disponible en la URL < http://manosteatrales.org>.

Pazy Melia, A., Catálogo de las piezas de teatro que se conservan en el Departamento de Manuscritos de la Biblioteca Nacional, tomo I, Madrid, Patronato de la Biblioteca Nacional, 1934 (segunda edición, revisada por Julián Paz Espeso). 
Pérez Pastor, C., Nuevos datos acerca del histrionismo español en los siglos XVI Y XVII. Primera Serie, Madrid, Imprenta de la Revista Española, 1901.

Reichenberger, K. y R., Bibliographisches Handbuch der Calderón-Forschung. Manual bibliográfico calderoniano, Kassel, Thiele \& Schwarz, 1979, vol. I.

Rennert, H. A., "Notes on the Chronology of the Spanish Drama», Modern Language Review, 2, 1906-1907, pp. 331-341.

Rocamora, J. M., Catálogo abreviado de los manuscritos de la biblioteca del Excmo.

Señor Duque de Osuna e Infantado, Madrid, Imprenta de Fortanet, 1882.

Ruano de la Haza, J. M., «Two Seventeenth-Century Scribes of Calderón», Modern Language Review, 73, 1978, pp. 71-81.

Sáez Raposo, F., Juan Rana y el teatro cómico breve del siglo xVII, Madrid, Fundación Universitaria Española, 2005.

Sentaurens, J., Séville et le théâtre. De la fin du Moyen Âge à la fin du XVIII siècle, Bourdeaux, Presses Universitaires, 1984, 2 vols.

Shergold, N. D. y Varey, J. E., "Some Early Calderón Dates», Bulletin of Hispanic Studies, 38, 1961, pp. 274-286. 